\title{
Key informants' perspectives on development of family medicine training programs in Ethiopia
}

This article was published in the following Dove Press journal:

Advances in Medical Education and Practice

27 April 2016

Number of times this article has been viewed

\author{
Weyinshet Gossa ${ }^{1,2}$ \\ Dawit Wondimagegn ${ }^{3}$ \\ Demeke Mekonnen ${ }^{4}$ \\ Wondwossen Eshetu ${ }^{5}$ \\ Zerihun Abebe ${ }^{6}$ \\ Michael D Fetters ${ }^{2}$ \\ 'Department of Family and \\ Community Medicine, University \\ of Maryland School of Medicine, \\ Baltimore, MD, USA; ${ }^{2}$ Department \\ of Family Medicine, University \\ of Michigan, Ann Arbor, MI, USA; \\ ${ }^{3}$ Department of Psychiatry, Addis \\ Ababa University, Addis Ababa, \\ ${ }^{4}$ Department of Pediatrics, Jimma \\ University, Jimma, ${ }^{5}$ Federal Ministry of \\ Health, 'St Paul's Hospital Millennium \\ Medical College, Addis Ababa, Ethiopia
}

Correspondence: Weyinshet Gossa Department of Family and Community Medicine, University of Maryland School of Medicine, 29 South Paca Street,

Baltimore, MD 2I20I, USA

$\mathrm{Tel}+\mathrm{I} 6672141812$

Fax +| 410685 |97|

Email wgossa@gmail.com

\begin{abstract}
As a very low-income country, Ethiopia faces significant development challenges, though there is great aspiration to dramatically improve health care in the country. Family medicine has recently been recognized through national policy as one potential contributor in addressing Ethiopia's health care challenges. Family medicine is a new specialty in Ethiopia emerging in the context of family medicine development in Sub-Saharan Africa. The Addis Ababa University family medicine residency program started in 2013 and is the first and the only family medicine program in the country as of March 2016. Stakeholders on the ground feel that family medicine is off to a good start and have great enthusiasm and optimism for its success. While the Ministry of Health has a vision for the development of family medicine and a plan for rapid upscaling of family medicine across the country, significant challenges remain. Continuing discussion about the potential roles of family medicine specialists in Ethiopia and policy-level strategic planning to place family medicine at the core of primary health care delivery in the country is needed. In addition, the health care-tier system needs to be restructured to include the family medicine specialists along with appropriately equipped health care facilities for training and practice. Key stakeholders are optimistic that family medicine expansion can be successful in Ethiopia through a coordinated effort by the Ministry of Health and collaboration between institutions within the country, other Sub-Saharan African countries, and international partners supportive of establishing family medicine in Ethiopia.
\end{abstract}

Keywords: primary health care, ethnography, residency program, Sub-Saharan Africa

\section{Introduction}

\section{Family medicine in Africa}

Family medicine has had roots in Africa for $>4$ decades. Family medicine training was first established in South Africa in 1968. In 1997, family medicine departments from all eight medical schools in South Africa and Ghent University in Belgium had a workshop in Durban, from which the "Durban Declaration" was developed. This was an agreement between the participating departments of family medicine to establish a network for communication and consultation, known as The Family Medicine Educational Consortium (FaMEC). ${ }^{1}$ In 2005, FaMEC reached out to family medicine departments in East African countries and developed a "South-South" collaboration, namely a collaboration within Africa that contrasted with a "North-South" collaboration with wealthy northern hemisphere countries. In 2007, the primary care/ family medicine education network (Primafamed) was formed to establish a network between universities with family medicine in Sub-Saharan Africa. ${ }^{1}$ In 2007, 39 years after the establishment of the first department of family medicine, the South African 
government officially recognized family medicine as a specialty. $^{2}$ In Sub-Saharan Africa, an area demarcated by 47 countries, 25 countries are developing family medicine training programs to address health care challenges of their respective countries. Ethiopia is an important case of family medicine development in Sub-Saharan Africa due to having substantive economic and health care challenges, while also having a vision for rapid expansion.

Ethiopia has some of the poorest health indicators in Africa and the world. Healthy life expectancy at birth is 55 years, under-five mortality 68 per 1,000 live births, and maternal mortality 420 per 100,000 live births. ${ }^{3}$ Communicable diseases account for the majority of the morbidity and mortality in the country. HIV/AIDS, tuberculosis (TB), malaria, and neglected tropical diseases are the major infectious diseases in Ethiopia. The HIV/AIDS prevalence is 827 per 100,000 population, TB prevalence 224 per 100,000 population, and malaria incidence 4,563 per 100,000 population. ${ }^{3}$ Chronic and non-communicable diseases account for $230 \%$ of deaths in Ethiopia. ${ }^{4}$ Approximately $80 \%$ of the burden of disease in Ethiopia is considered preventable. ${ }^{5}$

\section{Health care workforce issues in Ethiopia}

Despite Ethiopia's alarming health statistics, the government has committed to improve health care for its people, and major strides have been made toward this goal in the recent years. One of the approaches for improving Ethiopia's health care was through upscaling of the health care workforce in the country. In the years 2005-2009, the number of health care workers increased from 37,397 to 66,314 by training 12,595 nurses, 5,134 health officers, 2,070 physicians, and 31,804 health extension workers. ${ }^{6}$ However, a major physician shortage remains in Ethiopia due to historically low numbers of trainees exacerbated by brain drain of physicians who trained there but left the country. In 2009, government statistics demonstrated only $\sim 3$ physicians per 100,000 population. ${ }^{6}$ Ethiopia has a national health policy established in 1991 based on its primary health care system with a goal of ensuring accessibility of basic health care services including prevention, health promotion, cure, and rehabilitation. Ethiopia's Health Sector Development Plan IV for years 2011-2015 outlined the government's priorities for health for achieving this goal. Among these priorities are development of human resources for health including increasing the number of physicians and enhancing postgraduate training programs. ${ }^{7}$ The recognized need for establishment of family medicine in Ethiopia emerged out of these overarching priorities.

\section{Family medicine in Ethiopia}

Family medicine emerged in Ethiopia in the context of family medicine development in Sub-Saharan Africa. There is a growing recognition in Ethiopia that development of family medicine as a specialty could help address the country's health care challenges. Due to their broad training and adaptability, family medicine specialists can play a critical role in transforming the country's health care. The Ethiopian government has shown commitment for the development of family medicine in Ethiopia. In response to Ethiopia's health care challenges, the Ethiopian government developed a 20-year Health Sector Development Plan in 1997/1998 with completion of the first two phases in 2001 and 2005, respectively, and the fourth phase was under implementation from 2010 to 2015. The training and deployment of health extension workers was one of the strategies that developed out of the Health Sector Development Plan. This was an innovative approach to improve access to basic health care services by placing low-level health workers in the community, and the Ethiopian government earned praise for this internationally. Building health care facilities for improved health service coverage was another strategy, and though there has been an increase in the number of health posts, health centers, and hospitals, there is an ongoing endeavor to expand this further around the country. ${ }^{8}$ A number of health centers with improved capacities are being built around Addis Ababa, which is advantageous for family medicine development as family medicine specialists can train and work there, and this will eventually decrease the burden of service requirement on specialty hospitals. Similar expansion of health centers and upgrading of the existing regional health system can set the stage for expansion of family medicine at the regional level.

The first family medicine residency program was started in 2013 at the Addis Ababa University (AAU) in collaboration with the University of Toronto and the University of Wisconsin. While off to a good start, the program has faced challenges such as the need for further definition of the role of family medicine in Ethiopia, unclear future career paths for projected family medicine specialists, the need to develop curriculum in line with local needs, increasing the size of the program, and scarcity of Ethiopian family medicine faculty. ${ }^{9}$ There is also a need for further specification of clinical services provided by family medicine specialists and marketability and acceptability of the specialty to young trainees. ${ }^{10}$ Furthermore, it is important to develop strategies to limit exportation of the graduating Ethiopian family medicine specialists, so that they can remain in the country and promote growth of the specialty. Addressing these challenges 
and expanding family medicine into other hospitals are top priorities for family medicine development in Ethiopia.

The purpose of this research was to assess key stakeholders' perspectives on how to develop family medicine training programs in Ethiopia. Successful development of family medicine as a new discipline can be enhanced by assessment of stakeholders' views about training priorities and barriers needed to overcome. Given the severe physician shortage in Ethiopia, Ethiopian family medicine specialists will likely need solid training in surgical skills for common problems such as emergency trauma care, acute abdomen management, and medium-level obstetric and gynecologic care such as cesarean section and other operative delivery procedures. ${ }^{10}$ Hence, an assessment is needed to understand differences in opinion about what the scope of family medicine specialists' training should be, for setting specific training objectives ${ }^{11}$ and competencies, developing evaluation plans, and creating implementation strategies in line with the country's health care delivery system.

\section{Methods}

\section{Study design}

We conducted a mini-ethnography using the long interview method and field observations. Mini-ethnography is defined as a process of learning from people about aspects of their lives through defining questions, interviewing informants, observing, analyzing observations, and presenting findings over a short period of time. ${ }^{12}$ Primary data collection began months before entering the field, during a period of 2 weeks in the field, and over an extended time frame after leaving the field through email correspondence with informants and collaborators about an emerging understanding.

\section{Study setting}

This study was conducted in Addis Ababa and Jimma, Ethiopia. Ethiopia is a country with a population of estimated 96 million people. ${ }^{13}$ Addis Ababa is the capital city of Ethiopia, and Jimma is a city $350 \mathrm{~km}$ southwest of Addis Ababa. Data collection occurred at St Paul's Hospital Millennium Medical College, the AAU, and the Federal Ministry of Health in Addis Ababa and Jimma University in the city of Jimma.

St Paul's is a specialty hospital providing care to the underserved population in the outskirts of Addis Ababa. St Paul's launched its medical education program in 2008 and enrolls a total of 755 medical students in undergraduate and postgraduate programs yearly. There are currently five residency programs at St Paul's Hospital Millennium Medical College, ${ }^{14}$ and there are plans in place to add six additional programs. The hospital is also under a massive expansion from one to five hospitals, including the newly added kidney transplant center and construction that is underway for a women's and children's hospital and plans for cardiovascular and cancer centers.

Addis Ababa University School of Medicine is one of the oldest medical schools in Ethiopia. It is affiliated with Tikur Anbessa (Black Lion) Hospital, which is the largest specialty hospital with $\sim 700$ beds and a training center providing both undergraduate and postgraduate medical education. ${ }^{15}$ Addis Ababa University School of Medicine enrolls approximately 350 medical students per year.

Jimma University is known for providing communityoriented education. ${ }^{16}$ It has a total of 1,071 medical students. ${ }^{17}$ It is affiliated with Jimma University Specialized Hospital and is the only specialized and teaching hospital in southwestern Ethiopia. It serves a population of $\sim 15$ million and provides care to 15,000 inpatients, 160,000 outpatients, 11,000 emergency cases, and 4,500 deliveries annually. ${ }^{18}$

The Ethiopian Ministry of Health oversees various operations of the health sector. Headquartered in Addis Ababa, it sets standard for health services, determines qualifications of health care providers, conducts research, collaborates with development partners, and assesses implementation of health policies. ${ }^{8}$

\section{Data collection and analysis}

We utilized interviews and field observations for this study. Data collection and analysis occurred iteratively. The overarching qualitative approach utilized as described by Crabtree and Miller involved the following: 1) review of analytical categories (literature review), 2) review of cultural categories (researcher's implicit categories and preconceptions), 3) discovery of cultural categories (data collection), and 4) discovery of analytical categories (data analysis).${ }^{19}$ Literature review was conducted to learn about family medicine in Sub-Saharan Africa and Ethiopia. Based on the findings of the literature review, we generated a list of cultural categories, and interview questions were then created to elicit a narrative about these cultural categories. The interview process began with general questions, and follow-up probe questions were asked to complete the narrative. Key informants were identified based on prior knowledge of who is involved in the development of family medicine in Ethiopia and from suggestions on the ground. There were four formal meetings. Other informal meetings were held with individuals involved in medical education at St Paul's Hospital Millennium Medical College, AAU, and Jimma University. Formal interviews were digitally audio-recorded. 
Field jottings were taken during interviews, and then the ideas were discussed between two of the authors (WG and MDF) during regular meetings while in the field when they reflected about the day's events, discussed the importance and implications of each day's field work, and expanded the jottings and ideas into field notes. The audio-recorded interviews were reviewed and used to confirm field observations and field notes. The research was further informed by the question-and-answer sessions and ensuing dialogue generated by presentations (both presented twice) by two of the authors (MDF and WG) entitled "What can Family Medicine Do for Ethiopia?" and "A Day in the Life of a Family Physician", respectively.

\section{Data interpretation}

We used a modified SWOT (strength, weaknesses, opportunities, and threats) framework to analyze the data. To avoid potentially derogatory, judgmental, and value-laden language of "weaknesses", we substituted the concept of "challenges". During daily reflections about the day's events, interviews, field jottings, and observations, iteratively, the emerging ideas were consolidated into new questions for exploration. Over the course of the fieldwork and subsequent analysis of transcripts of interviews, we organized the findings into the SCOT framework of strengths, challenges, opportunities, and threats to delineate the status of family medicine in Ethiopia.

\section{Ethical issues}

This study was exempted from needing full ethical approval and obtaining informed consent from the participants because there were no vulnerable individuals or minors participating and no identifying information was collected. This study was reviewed and exempted by the institutional review board of the University of Michigan. The institutional review board approval from the University of Michigan was accepted by the partnering academic institutions: Addis Ababa University, St Paul's Hospital Millennium Medical College, and Jimma University. Cultural norms were taken into consideration throughout the entire study.

\section{Results}

As a mini-ethnography, this paper presents key informants' perspectives on the development of family medicine in Ethiopia. The SCOT framework was applied to organize the researchers' observations and stakeholders' views about family medicine as a new discipline in Ethiopia, the current family medicine residency program, and planning for new residency programs (Tables 1-4). The main points are presented and organized by national, institutional, and program levels.
Table I Strengths of family medicine development in Ethiopia

\section{National}

- Advancement of Ethiopia's health care is a priority for the country.

- There is a strong support from the Ethiopian Federal Ministry of Health for expansion of family medicine training programs in Ethiopia.

- The Federal Ministry of Health is helping in recruiting residents into family medicine.

- The ongoing expansion of medical student numbers across the country will increase the pool of applicants for all residency program expansions including family medicine.

- The first family medicine residency program is successfully established.

- The Federal Ministry of Health is supporting expansion of family medicine to Jimma and Gondar Universities.

- Family medicine is developing in Ethiopia in the context of family medicine developing in other African countries legitimizing family medicine across Africa.

- Ethiopia's health extension workers program is praised internationally and the envy of many African countries.

- There are new health centers that are being built around Addis Ababa with improved capacity for diagnosis and treatment.

Institutional

- The Addis Ababa University College of Health Sciences and the dean of the Addis Ababa University Medical School are very supportive of family medicine.

- There is support for the Addis Ababa University family medicine program from international partners from the University of Toronto, the University of Wisconsin, and the Medical Education Partnership Initiative program.

- Some of the graduating family medicine specialists have become faculty at Addis Ababa University.

- Jimma University has $>30$ years of community engagement experience positioning it well for future development of family medicine residency program.

Program

- There is support from core specialists including internal medicine, pediatrics, and psychiatry who are involved in training of family medicine residents at Addis Ababa University.

- The Addis Ababa University's family medicine residency program director believes in the vision of the program.

- Curriculum and objectives of the Addis Ababa University's family medicine residency program are outlined and revised based on residents' experiences.

- The Addis Ababa University family medicine program includes training in multiple hospitals around Addis Ababa and in a community health center.

- The current Addis Ababa University's family medicine residents are very committed to the specialty.

\section{Strengths}

There are several strengths of family medicine in Ethiopia (Table 1). At the national level, the Ministry of Health is very supportive of family medicine development in Ethiopia, is taking initiatives to help with recruitment of family medicine residents to the existing program, and is supporting establishment of new programs at Jimma and Gondar Universities. Ethiopia has successfully established its first family medicine residency program and now has 
Table 2 Challenges to family medicine development in Ethiopia

\section{National}

- Ethiopia's health care system is under-capacity for meeting the health care needs of the country.

- Family medicine as a specialty is not well understood by the medical community, though family medicine leaders think that the public understands and embraces the idea of family medicine specialists.

- There is a lack of established Ethiopian family medicine specialists in Ethiopia.

- Level of buy-in from GPs, other specialists, and health extension workers varies from uncertainty and ambivalence to suspicion.

- Despite vision at the highest level about what family medicine would look like, family medicine's roles are still evolving and still not clearly defined.

\section{Institutional}

- Family medicine leaders in Ethiopia now are other specialists who have heard and/or learned about family medicine but have not had first-hand experience as family medicine specialists.

- There is a limited number of family medicine-trained faculty to teach residents.

- The current faculty are still developing ways of teaching family medicine residents.

- A system of mentorship and faculty development is still in the early stages of development.

\section{Program}

- There is competition from other residents for clinical training opportunities when residents rotate in hospitals that have residents in the specialty that they are rotating in.

- There are highly limited financial resources to pay for resident salary, for residents to attend international conferences, for research, to pay community specialists to provide training, and for a learning resource center

- Expectations about what family medicine residents should learn and how they should be evaluated on are still under development, though there is ongoing iterative development at Addis Ababa University.

- Addis Ababa University's family medicine program started at a large medical center and in the city, but the setting where the majority of family medicine specialists will practice will likely be different.

- Currently, there is no family medicine experience at the undergraduate level.

- Without considerable push from the Ministry of Health, recruiting medical students into family medicine to attain the goal of $50 \%$ family medicine specialists and $50 \%$ other specialists will be difficult.

Abbreviation: GP, general practitioner.

its own home-trained family medicine specialists with the first class graduation in January of 2016. This is a huge step for the country as these family medicine specialists will be pioneers of the specialty. They will be leaders of family medicine in the country and will train future family medicine specialists among other roles they will assume. The planning for family medicine programs at Jimma and Gondar Universities is underway, and the programs are planned to start in the near future.

At the institutional level, there is a strong support for family medicine at AAU. AAU has strong collaborative international partners from North America who have helped
Table 3 Opportunities for family medicine development in Ethiopia

\section{National}

- There is a high need for quality and comprehensive primary care that family medicine can provide.

- The Ministry of Health actively seeks to upscale the current primary care health care system.

- There is an increasing number of postgraduate training programs by the Ministry of Health including family medicine.

- There is a gap between primary care provided by GPs, health officers, and health extension workers and other specialty care that family medicine specialty can fill.

- There is an opportunity for family medicine specialists to be health care system leaders.

\section{Institutional}

- The increasing number of medical school graduates provides an increasing pool of potential future family medicine residents.

- If done well, experienced GPs looking for specialty certification could join family medicine after serving time as self-made family physicians.

Program

- There is only one family medicine residency program currently, and this leaves a lot of space for other programs to emerge.

- The existing family medicine program is producing family medicine graduates who can lead family medicine growth in Ethiopia.

- The Ministry of Health is allowing some medical school graduates to join specialty training without serving their time as a GP, and the family medicine specialty is given a preference at this time.

- Potential internal and external brain drain of graduating family medicine specialists could threaten the viability of the specialty.

Abbreviation: GP, general practitioner.

start the program and are providing ongoing support. Some of the family medicine graduates have become faculty at AAU. As they have experienced family medicine first hand, they will help strengthen the already existing leadership of the program and further refine the current curriculum and objectives. The presence of Ethiopian family medicine faculty will lead to a better representation of the specialty

Table 4 Threats to family medicine development in Ethiopia

\section{National}

- There is a risk that other specialists, GPs, and health extension workers will perceive family medicine specialists as competitors with their own work and viability.

\section{Institutional}

- The increasing number of postgraduate training programs can create strain on human, financial, and material resources.

\section{Program}

- The frequent turnover in leadership of the existing family medicine program is concerning for future stability of the program.

- There are limited opportunities for leadership and research training for current family medicine residents.

- Extensive responsibilities could be overwhelming for graduating family medicine residents and could lead to burn out and drop out.

- Potential internal and external brain drain of graduating family medicine specialists could threaten the viability of the specialty.

Abbreviation: GP, general practitioner. 
and stronger relationships with other specialists at the institution. Further, the family medicine program at AAU will serve as a good example and resource for upcoming family medicine programs at Jimma and Gondar Universities. Jimma University has $>30$ years of experience in community-based education and can successfully develop a family medicine program by learning from experiences of AAU.

At the ground level, the AAU program is off to a good start. From one informant's perspective, "Most things are going well ... provided that this is a new program in the country, it is going well". Both the program director and the residents are very committed to the program and the specialty of family medicine. There is support from the core specialists including internal medicine, pediatrics, surgery, obstetrics and gynecology, and psychiatry who are involved in training of the family medicine residents at AAU. Curriculum and objectives of the AAU program are outlined and revised regularly based on residents' experiences. The training encompasses rotations at multiple hospitals around Addis Ababa and community health centers providing a well-rounded experience to the residents.

\section{Challenges}

Despite aforementioned strengths, family medicine in Ethiopia also faces a number of challenges (Table 2). At the national level, Ethiopia's health care system cannot meet the health care needs of the country. This is due to limited human, financial, and material resources as well as a limited infrastructure. The Ethiopian population is growing at a fast pace with increasing demand for health care services beyond the health care system's capacity. The Ethiopian government is striving to strengthen the health care system, and family medicine development is part of this strategic plan. However, given that family medicine is a new discipline in the country and the current Ethiopian family medicine specialists are new graduates and very few in number, it is not well known or understood. This makes it difficult to gain strong buy-in from other specialists, general practitioners (GPs), and health extension workers. Additionally, the roles of family medicine are still evolving and not clearly defined. Most of the family medicine graduates are expected to become "leaders, educators, and advocates" of the specialty. Continual discussion on potential roles of family medicine in Ethiopia is needed, especially as new programs are being started. It will be very important to develop a common vision for family medicine in Ethiopia.

At the institutional level, there are limited numbers of faculty to teach family medicine residents and for mentorship. Family medicine leaders now are other specialists who have heard and/or learned about family medicine but have not had first-hand experience as family medicine specialists. It will take many years before developing a pool of Ethiopian family medicine faculty. Until then, the programs will need to rely on faculty from other specialties and international family medicine faculty. There are limited opportunities for leadership training and faculty development for the graduating residents; these need to be incorporated into family medicine training in order to cultivate strong pool of future family medicine faculty. Although there are established curriculum and objectives for family medicine at AAU, the faculty are still developing strategies on how to teach family medicine residents due to the unique nature of such training.

At the program level, family medicine residents struggle with competition from other residents, especially in obtaining appropriate surgical experiences. There are limited finances to pay for resident salaries, to send residents for international conferences, and to invest in research and learning resource centers. There is also a limited availability of books and online learning resources. The learning objectives and evaluations of family medicine residents are still under development, though there is ongoing iterative development at AAU. AAU's family medicine program started at a large medical center in a major city, but the majority of family medicine specialists will likely practice in different settings. It is important to include training opportunities in similar settings as those where family medicine specialists will practice. As family medicine expands to the regional level, it will be important to develop curricula according to the local needs. Involving the local medical education experts early in the planning phase is crucial for successful development of the programs.

\section{Opportunities}

As there are challenges, there are also a lot of opportunities for family medicine growth in Ethiopia (Table 3). At the national level, there is a high need for quality, comprehensive primary health care, and the Ministry of Health is committed to upscale family medicine training to meet this need. There is an increasing number of postgraduate training programs by the Ministry of Health, which includes family medicine. There is a great optimism that family medicine can help turn around the country's health care challenges. According to one informant, family medicine can provide "cost effective, systematical, desirable, patient-based, and humane" care. In the current model, the primary health centers are staffed only by health officers, nurses, and nurse midwives but not doctors. The majority of patients are referred to tertiary care 
centers. This creates excessive demand for subspecialty care limiting access for those who really need such care. Family medicine specialists will be able to bridge this gap in care provided by health extension workers, GPs, and other specialists. They will help improve access to both first contact and specialty care. This can be made possible by having policy that supports family medicine as the foundation of primary health care in the country. One informant stated, "We can keep on training, but unless the policy framework is there to base primary health care service with a family medicine foundation, we will struggle". Family medicine specialists will also have unique opportunities to become health system leaders, manage population health, conduct needs-based research, and educate the next generation of family medicine specialists.

At the institutional level, the increasing number of medical school graduates provides a pool of potential future family medicine trainees. This will help in meeting the goal of having at least $50 \%$ of the graduating medical students join family medicine. Early exposure to family medicine at the undergraduate level and advocacy for the specialty by the Ministry of Health will be important in achieving this goal. Another approach that may prove beneficial is a system that allows current GPs to obtain the necessary training to become a family medicine specialist. They could benefit by obtaining a specialist status while helping to increase the number of trained family medicine specialists.

At the program level, there is only one family medicine residency program as of March 2016, and this leaves a lot of room for other programs to emerge. The existing family medicine program is producing family medicine graduates who can lead family medicine growth in Ethiopia. The Ministry of Health is allowing some medical school graduates to join specialty training through a waiver of mandatory service requirement for all medical students immediately after graduation as GPs. Thus far, family medicine specialty is being given a preference. This is extremely valuable for recruitment of prospective family medicine residents, especially as new programs get started.

\section{Threats}

Although there are ample opportunities for family medicine success in Ethiopia, there are important threats to consider (Table 4). At the national level, although there is a vision at the highest level for development of family medicine as a specialty, there is a concern that this may not be done in a scientifically sound manner. It is very important to develop family medicine as a scientific discipline like any other specialty of medicine as to not compromise the credibility and prestige of the specialty. There is ambivalence from other specialists, GPs, and health extension workers about the potential for competition from family medicine specialists. This stems mostly from limited understanding of the role of family medicine specialty in the larger health care system. Better definition of the roles of family medicine and increasing the number of Ethiopian family medicine specialists in practice can aid in better understanding and acceptance of the specialty.

At the institutional level, although support from wealthy northern countries is essential for initial phase of family medicine development, this has a potential to undermine local capacity building and threaten long-term sustainability of the programs. There needs to be local ownership of the programs. This along with opportunities for career advancement will be essential in helping limit potential brain drain of family medicine specialists. One strategy is to develop special tracks within residency training programs and by adding family medicine fellowship programs. The increasing number of residents in different specialties may create further strain on human, financial, and material resources leading to limited opportunities for training and poor quality education. It will be very important to develop innovative methods to capitalize on available resources and to put in place quality measures for the programs.

At the program level, the frequent turnover in leadership of the existing family medicine program is concerning for future stability of the program. Stable leadership is needed in the early years of the existing and upcoming programs for their future success. There are limited opportunities for leadership and research training for current family medicine residents. Training in leadership, health management, faculty development, and research should be an integral part of family medicine training. Extensive responsibilities could be burdensome to the graduating family medicine residents and could lead to burn out and drop out contributing to both internal and external brain drain. Having continuous medical education and opportunities for career advancement could help with job satisfaction and faculty retention.

\section{Discussion}

Based on this research, it can be concluded that there is much enthusiasm about the development of family medicine and an optimism for the success of the specialty in Ethiopia. There is a sense that family medicine has "turned the corner" in Ethiopia despite remaining significant challenges. On the ground, some participants felt as though convincing 
the Ministry of Health about the importance of family medicine was the biggest challenge and overcoming this is seen as a big accomplishment in the development of family medicine in Ethiopia. Family medicine development in Sub-Saharan Africa has been described using the stages of change model with five stages: pre-contemplation, contemplation, action, maintenance, and relapse with different countries at different stages of family medicine development. ${ }^{20}$ Using this model, Ethiopia is at the action phase with its plan to expand from one to three family medicine programs in the coming year.

The experiences gained and expertise developed with the successful establishment of the first family medicine program at AAU are a valuable asset in forming upcoming programs. Contributions of family medicine educators from University of Toronto and University of Wisconsin, Madison, were particularly impactful based on a recently completed Medical Education Partnership Initiative grant. Collaboration between AAU, University of Toronto, and University of Wisconsin faculty was instrumental in the planning and implementation of the AAU family medicine program. The process of developing the first family medicine program in Ethiopia was outlined in their paper "The Dawn of Family Medicine in Ethiopia". The collaborative relationship between these institutions still continues through the early years of the program. It remains unclear how training needs will evolve over time. In particular, uncertainty remains whether the rapid expansion of medical student trainees with anticipated increases in all residents and eventual increases in all specialties, including surgeons, will diminish the needs for some skills, for example, surgical skills. Nonetheless, if done well, the rapid expansion of family medicine in Ethiopia can serve as a good model for family medicine development in other African countries. Similarly, Ethiopia's family medicine development can get ahead by collaborating with other Sub-Saharan African countries, through sharing experiences, expertise, and resources.

Ethiopia has shown one of the highest development rates in the world in the past decade. ${ }^{21}$ The implementation of the health extension workers program is one of the internationally recognized achievements in the health sector. This has shown Ethiopia's potential and determination to improve the health care of the country. Opportunity is ripe for family medicine development in Ethiopia as the government has made a priority to strengthen the primary health care system, and family medicine is at the center of this goal. Even though Ethiopia is very early in the development of family medicine compared to Sub-Saharan African countries such as South Africa, Nigeria, and Ghana, its prior successes can serve as a fuel for the rapid expansion of family medicine in the country. Ethiopia like other African countries is answering to the 1978 declaration of Alma-Ata that called for primary health care for all ${ }^{22}$ and the 2008 World Health Report that emphasized the need for reforms in universal coverage, people-centered services, public policy, and leadership in primary health care for more coherent, efficient, equitable, and effective health systems. ${ }^{23}$ Ethiopia is making strides toward achieving this goal, and the expansion of family medicine will move the country one step closer to realizing a comprehensive, quality, and equitable primary health care for all.

Many challenges facing family medicine development in Ethiopia are similar to challenges seen in other African countries. Some of the common challenges are: limited capacity of the health care system, limited number of local family medicine specialists, unclear roles of family medicine specialists in the overall health care system, limited finances, limited awareness about family medicine, and lack of family medicine teaching at the undergraduate level. ${ }^{24}$ Although these challenges need to be addressed in the context of each individual country, it is important that this be done in collaboration with other Sub-Saharan African countries. The value of South-South collaboration has been demonstrated through the Primafamed project in which ten Sub-Saharan African countries worked together in development of family medicine training programs in their respective countries. ${ }^{24}$ The Stellenbosch University Rural Medical Education Partnership Initiative was developed under the umbrella of the Medical Education Partnership Initiative program to address rural medical education program in Africa and has provided assistance in addressing challenges facing family medicine programs in Sub-Saharan African countries. ${ }^{20}$ Ethiopia and the other African countries will need continuation of similar collaborative efforts for successful upscaling of family medicine programs throughout the continent.

\section{Conclusion}

Family medicine as a new discipline in Ethiopia is off to a promising start, and there is a vision at the highest level and support for a rapid expansion of the specialty. Nonetheless, family medicine faces significant challenges similar to other Sub-Saharan African countries that need to be addressed in both Ethiopian and African contexts for success of the specialty and to obtain intended outcomes for the country. International collaborations have provided tangible outcomes. An ongoing dialogue is needed to further define the potential roles of family medicine specialists in the overall health care system. A policy framework is needed to make family 
medicine the foundation for the country's primary health care system. With this support, family medicine specialists can work collaboratively with the existing primary health care workforce for the delivery of quality and comprehensive primary health care with the end goal of improving the health of the population. Given the limitation of resources, institutions with family medicine programs will need to work together to share resources and expertise. In addition, until enough numbers of Ethiopian family medicine specialists are generated, the institutions will continue needing external support for teaching and mentorship, which thus far has been done primarily through "North-South" collaborations; however, it is essential to develop "South-South" collaborations going forward. African countries face common challenges and can overcome these challenges by working together toward their common goal of upscaling family medicine programs to improve primary health care for their respective countries and for the continent.

\section{Acknowledgments}

This work was made possible in part through the generous support of St Paul's Hospital Millennium Medical College and the University of Michigan Department of Family Medicine.

\section{Disclosure}

The authors report no conflicts of interest in this work.

\section{References}

1. Kidd MR, World Organization of National Colleges Academies and Academic Associations of General Practitioners/Family Physicians. The Contribution of Family Medicine to Improving Health Systems: A Guidebook from the World Organization of Family Doctors. 2nd ed. London: Radcliffe Publishing Ltd; 2013.

2. Hellenberg D, Gibbs T. Developing family medicine in South Africa: a new and important step for medical education. Med Teach. 2007; 29(9):897-900.

3. World Health Organization: Regional Office for Africa. Ethiopia: Country Health Profile; 2012 [updated 2015]. Available from: http://www.afro.who. int/en/ethiopia/country-health-profile.html. Accessed June 5, 2015.

4. World Health Organization. Noncommunicable Diseases (NCD) Country Profiles, 2014: Ethiopia; 2014. Available from: http://www.who.int/nmh/ countries/eth_en.pdf?ua=1. Accessed June 5, 2015.

5. World Health Organization. WHO Country Cooperation Strategy: Ethiopia; 2012-2015. Available from: http://www.who.int/countryfocus/ cooperation_strategy/ccs_eth_en.pdf?ua=1. Accessed June 5, 2015 .
6. African Health Workforce Observatory AHWHO. Human Resources for Health - Country Profile, Ethiopia; 2010. Available from: http:// www.hrh-observatory.afro.who.int/images/Document_Centre/Country_ profile_Ethiopia.pdf?ua=1. Accessed June 5, 2015.

7. Federal Democratic Republic of Ethiopia Ministry of Health. Health Sector Development Plan IV 2010/11 - 2014/15; 2010. Available from: http:// www.nationalplanningcycles.org/sites/default/files/country_docs/Ethiopia/ ethiopia_hsdp_iv_final_draft_2010_-2015.pdf. Accessed June 5, 2015.

8. Federal Democratic Republic of Ethiopia: Ministry of Health. About the Ministry: Programs and Projects. Available from: http://www.moh. gov.et/programsprojects. Accessed December 27, 2015.

9. Philpott J, Cornelson B, Derbew M, et al. The dawn of family medicine in Ethiopia. Fam Med. 2014;46(9):685-690.

10. Gossa W, Fetters M, Zazove P. The dawn of family medicine in Ethiopia. Fam Med. 2015;47(2):148.

11. Bland CJ, Houge DR, Hofstrand HJ, Filiatrault LJ, Gunkler JW. Developing an objective based curriculum for a family practice residency. J Fam Pract. 1977;4(1):103-110.

12. Weinstein J, Ventres W. Mini-ethnography: meaningful exploration made easy. Fam Med. 2000;32(9):600-602.

13. Central Intelligence Agency. The World Fact Book. Available from: https://www.cia.gov/library/publications/resources/the-world-factbook/ geos/et.html. Accessed December 15, 2015.

14. Alemayehu B. St Paul's Hospital Millennium Medical College: academics. Available from: http://www.sphmmc.edu.et/index.php/ academic.html. Accessed June 10, 2015.

15. Dagne M, Haleluya K. Addis Ababa University College of Health Sciencies: background; [updated 2015]. Available from: http://www. aau.edu.et/chs/. Accessed June 10, 2015.

16. Jimma University. Community based education (CBE) philosophy of the college; [updated 2015]. Available from: http://www.ju.edu.et/ cphms/node/175. Accessed June 10, 2015.

17. Jimma University. Historical background; [updated 2015]. Available from: http://www.ju.edu.et/cphms/node/97. Accessed June 10, 2015.

18. Jimma University. Jimma University Specialized Hospital. Available from: http://www.ju.edu.et/jimma-university-specialized-hospital-jush. Accessed June 10, 2015.

19. Crabtree BF, Miller WL. A qualitative approach to primary care research: the long interview. Fam Med. 1991;23(2):145-151.

20. Mash RJ, de Villiers MR, Moodley K, Nachega JB. Guiding the development of family medicine training in Africa through collaboration with the Medical Education Partnership Initiative. Acad Med. 2014;89 (8 Suppl):S73-S77.

21. UNDP. National Human Development Report 2014: Ethiopia. Available from: http://hdr.undp.org/sites/default/files/nhdr2015-ethiopia-en.pdf. Accessed June 22, 2015.

22. World Health Organization. Declaration of Alma-Ata. Available from: http://www.who.int/publications/almaata_declaration_en.pdf. Accessed June 21, 2015.

23. World Health Organization. World Health Report 2008: Primary Health Care (Now More Than Ever); [updated 2015]. Available from: http:// www.who.int/whr/2008/en/. Accessed June 21, 2015.

24. Flinkenflogel M, Essuman A, Chege P, Ayankogbe O, De Maeseneer J. Family medicine training in sub-Saharan Africa: South-South cooperation in the Primafamed project as strategy for development. Fam Pract. 2014;31(4):427-436.

\section{Publish your work in this journal}

Advances in Medical Education and Practice is an international, peerreviewed, open access journal that aims to present and publish research on Medical Education covering medical, dental, nursing and allied health care professional education. The journal covers undergraduate education, postgraduate training and continuing medical education

\section{Dovepress}

including emerging trends and innovative models linking education, research, and health care services. The manuscript management system is completely online and includes a very quick and fair peer-review system. Visit http://www.dovepress.com/testimonials.php to read real quotes from published authors. 